\title{
Propriedades farmacológicas da Aloe vera: uma revisão integrativa
}

\author{
Pharmacological properties of Aloe vera: an integrative review \\ Propiedades farmacológicas del Aloe vera: una revisión integradora
}

Recebido: 22/01/2022 | Revisado: 30/01/2022 | Aceito: 06/02/2022 | Publicado: 12/02/2022

José Severiano Barbosa Filho

ORCID: https://orcid.org/0000-0001-7232-2875

Faculdade Santíssima Trindade, Brasil

E-mail: barbosafarmaclin@hotmail.com

José Severino de Oliveira Filho

ORCID: https://orcid.org/0000-0001-8971-5747

Faculdade Santíssima Trindade, Brasil

E-mail: godo.oliveira@hotmail.com

Erika Gabrielly De Oliveira Gomes

ORCID: https://orcid.org/0000-0002-9702-1101

Faculdade Santíssima Trindade, Brasil

E-mail: erikagabrielly90@gmail.com

Maiane Silva Barbosa de Moraes

ORCID: https://orcid.org/0000-0001-9089-165X

Faculdade Santíssima Trindade, Brasil

E-mail: maianebmoraes@gmail.com

Aprigio Tavares Pessôa Filho

ORCID: https://orcid.org/0000-0002-2606-7217

Faculdade Santíssima Trindade, Brasil

E-mail: aprigiotavares@hotmail.com

Evelyne Joyce Dias Oliveira

ORCID: https://orcid.org/0000-0003-2846-3114

Faculdade Santíssima Trindade, Brasil

E-mail: evelynedias123@gmail.com

José William Araújo do Nascimento ORCID: https://orcid.org/0000-0002-1844-1117

Universidade Federal de Pernambuco, Brasil E-mail: jwan@cin.ufpe.br

Dário César de Oliveira Conceição ORCID: https://orcid.org/0000-0002-0543-2764 Faculdade Santíssima Trindade, Brasil E-mail: dariodeoliveira89@gmail.com

\begin{abstract}
Resumo
Objetivo: Identificar as principais propriedades farmacológicas da Aloe vera. Metodologia: Trata-se de uma revisão integrativa realizada nas bases de dados eletrônicas LILACS, SciELO e PubMed, por meio dos seguintes descritores: "Aloe vera", "Substâncias Isoladas" e "Atividades Biológicas". Foram incluídos artigos completos, disponíveis em português e inglês, publicados entre janeiro de 2011 a dezembro de 2021. Resultados: A amostra final foi composta por 07 artigos, publicados no intervalo anual entre 2011 a 2020. Em relação à abordagem dos artigos encontrados, verifica-se que a maior parte utilizou o estudo experimental (n: 05), com nível de evidência moderado (III), seguido do ensaio clínico randomizado (n: 02), com nível de evidência forte (II). As principais propriedades farmacológicas identificadas da Aloe vera foram sua ação anti-inflamatória (redução de eritema, exsudato e dor), antimicrobiana, antioxidante, cicatrizante (redução do tempo para cicatrização de feridas agudas e crônicas) e hipoglicemiante (inibição de elevação da glicose pós-prandial). Conclusão: Numerosas atividades biológicas foram atribuídas a Aloe vera ao longo dos anos, especialmente por causa da combinação dos diversos compostos ativos existentes em sua composição. Verificou-se que esta planta medicinal possui diversos efeitos farmacológicos, como ação antiinflamatória, antimicrobiana, antioxidante, cicatrizante e hipoglicemiante.
\end{abstract}

Palavras-chave: Aloe vera; Fitoterapia; Plantas Medicinais.

\begin{abstract}
Objective: To identify the main pharmacological properties of Aloe vera. Methodology: This is an integrative review carried out in the electronic databases LILACS, SciELO and PubMed, using the following descriptors: "Aloe vera", "Isolated Substances" and "Biological Activities". Full articles, available in Portuguese and English, published between January 2011 and December 2021 were included. Results: The final sample consisted of 07 articles, published in the annual interval between 2011 and 2020. Regarding the approach of the articles found, check Most of
\end{abstract}


them used the experimental study (n: 05), with a moderate level of evidence (III), followed by the randomized clinical trial (n: 02), with a strong level of evidence (II). The main pharmacological properties identified of Aloe vera were its anti-inflammatory action (reduction of erythema, exudate and pain), antimicrobial, antioxidant, healing (reduction of time for healing of acute and chronic wounds) and hypoglycemic (inhibition of post-hyperglycemic glucose elevation). -prandial). Conclusion: Numerous biological activities have been attributed to Aloe vera over the years, especially because of the combination of the various active compounds in its composition. It was found that this medicinal plant has several pharmacological effects, such as anti-inflammatory, antimicrobial, antioxidant, healing and hypoglycemic action.

Keywords: Aloe vera; Phytotherapy; Plants, Medicinal.

\section{Resumen}

Objetivo: Identificar las principales propiedades farmacológicas del Aloe vera. Metodología: Se trata de una revisión integradora realizada en las bases de datos electrónicas LILACS, SciELO y PubMed, utilizando los siguientes descriptores: "Aloe vera", "Sustancias aisladas" y "Actividades biológicas". Se incluyeron artículos completos, disponibles en portugués e inglés, publicados entre enero de 2011 y diciembre de 2021. Resultados: La muestra final estuvo compuesta por 07 artículos, publicados en el intervalo anual entre 2011 y 2020 . En cuanto al abordaje de los artículos encontrados, consulte La mayoría de ellos utilizaron el estudio experimental (n: 05), con un nivel de evidencia moderado (III), seguido del ensayo clínico aleatorizado (n: 02), con un nivel de evidencia fuerte (II). Las principales propiedades farmacológicas identificadas del Aloe vera fueron su acción antiinflamatoria (reducción del eritema, exudado y dolor), antimicrobiana, antioxidante, cicatrizante (reducción del tiempo de cicatrización de heridas agudas y crónicas) e hipoglucemiante (inhibición de la elevación de la glucosa posprandial). Conclusión: A lo largo de los años se le han atribuido numerosas actividades biológicas al Aloe vera, especialmente por la combinación de los distintos principios activos en su composición. Se encontró que esta planta medicinal tiene varios efectos farmacológicos, como acción antiinflamatoria, antimicrobiana, antioxidante, cicatrizante e hipoglucemiante.

Palabras clave: Aloe vera; Fitoterapia; Plantas Medicinales.

\section{Introdução}

A Aloe vera está presente na literatura de inúmeras culturas, fato que leva a pressupor que sua história é antiga. O primeiro registro do uso da Aloe vera foi feito na Mesopotâmia, datada em 2100 a.C. Em seguida encontra-se registros de seu uso no Egito Antigo, sendo então trazida para o Brasil através de comerciantes para o mercado londrino em 1693 (Freitas et al., 2014).

A Babosa, como é popularmente conhecida, apresenta bordas envoltas de dentes espinhosos triangulares curtos e espaçados. Suas folhas são estratificadas em duas partes principais, uma externa onde se destaca a casca verde formada pela epiderme, parênquima clorofiliano e feixes vasculares e outra que em seu interior apresenta um tecido mucilaginoso e incolor, denominado de polpa ou gel da folha (Souza et al., 2020).

A Aloe vera é um membro entre as mais de 400 espécies pertencentes à família Liliaceae, frequentemente utilizado para fins terapêuticos. É uma planta tropical crescida facilmente em climas subtropicais e tropicais secos, incluindo o Brasil (Maenthaisong et al., 2007). A composição química difere a depender das condições ambientais entre as espécies de Liliaceae pois elas são bastante semelhantes entre si, podendo ocorrer em algumas, maior concentração de compostos do que em outras, a depender da qualidade do ambiente onde o vegetal se encontra (Souza et al., 2017).

Ela é bastante difundida por suas propriedades bioativas destinadas ao mercado farmacêutico, nutracêutico e estético. A composição química da planta varia, dependendo do clima e condições de crescimento. Em geral, ela contém 75 constituintes potencialmente ativos relatados, como vitaminas, enzimas, minerais, açúcares, lignina, saponinas, ácidos salicílicos e aminoácidos (Farias, 2020).

Esta planta tem seus princípios ativos concentrados nas folhas, onde seu interior é composto por tecido parenquimático, rico em polissacarídeos (mucilagem), atribuindo-lhe uma consistência viscosa. Os princípios ativos são encontrados na mucilagem, na seiva e na casca, sendo os principais a aloína (glicosídio da antraquinona), aloemodina, aloeferon, aloetina e barboladina, que são os agentes responsáveis pelas propriedades medicinais da planta. Além destes, há 
polissacarídeos, silicatos, salicilatos, lactato de magnésio, taninos e resinas (Bontempo, 2012).

A Aloe vera apresenta ações laxativas e vermífugas, sendo utilizadas com eficiência no tratamento de acnes, cortes (como auxiliar cicatrizante), asma, tosse, queimaduras, feridas, abrasões, algumas doenças de pele, hemorroidas, caspa, dores de garganta, problemas digestivos e circulatórios e diabetes mellitus. Esta planta também possui ação bactericida, antifúngica e antiviral, sendo esta última devido a presença de antraquinonas, que apresentam elevado potencial antimicrobiano, principalmente por ocasionarem a lise das cápsulas que envolvem os vírus (Vignini, 2011; Lima et al., 2012; Pereira et al., 2020). Neste contexto, este estudo objetivou identificar as principais propriedades farmacológicas da Aloe vera.

\section{Metodologia}

Foi realizado um estudo de revisão integrativa da literatura. Os estudos foram selecionados a partir de pesquisas nas bases de dados: Literatura Latino-americana e do Caribe em Ciências da Saúde (LILACS), Scientific Eletronic Libray Online (SciELO) e Nacional Institute of Medicine (NIH-PUBMED), no período de novembro a dezembro de 2021. Realizou-se consulta ao Medical Subject Headings (MeSH) e ao Descritores em Ciencias da Saude (DeCS). Foram utilizados os seguintes descritores: "Aloe vera", "Babosa", "Produtos Biológicos" e "Biological Products".

Os artigos selecionados atenderam aos seguintes critérios de inclusão: pesquisas disponíveis eletronicamente nas bases de dados selecionadas e publicadas em português ou inglês entre 2011 e 2021. Foram tomados os seguintes critérios de exclusão: duplicatas, estudos com temática não relevante ao objetivo da pesquisa, estudos de revisão e relatos de caso.

Para garantir o registro conjunto de informações relevantes ao tema, foi utilizado o instrumento proposto por Nascimento et al. (2021), adaptado para este estudo com as seguintes variáveis: dados de identificação (título, autores, periódico, ano de publicação, país de origem do estudo e base de dados), delineamento metodológico, nível de evidência e principais resultados.

Após a aplicação dos filtros de pesquisa nas bases de dados, inicialmente foram encontrados 347 artigos, de modo que os artigos duplicados foram registrados apenas uma vez, totalizando em 321. Após a leitura dos títulos e resumos simultaneamente foram excluídas 263 publicações que não tinham abordagem relevante a temática deste estudo e 12 estudos de revisão. Sendo assim, 46 publicações foram selecionadas para leitura na íntegra. Foram excluídas 39 publicações, de tal modo que 07 estudos foram incluídos na amostra final, conforme se observa na Figura 1. 
Figura 1: Fluxograma do processo de seleção do estudo, 2022.

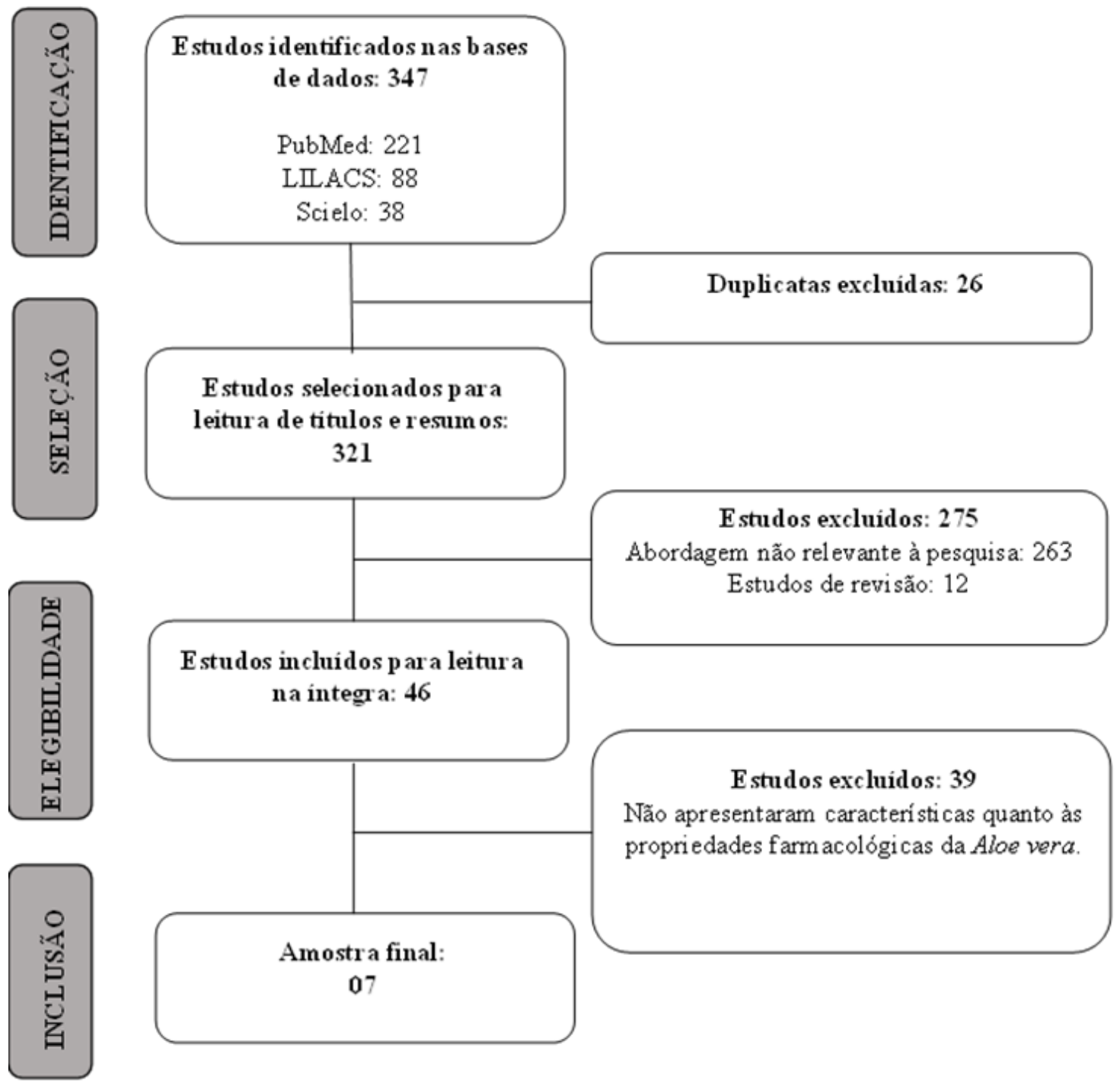

Fonte: Autores.

Os artigos selecionados foram submetidos à classificação do nível de evidência, a partir do instrumento de Classificação Hierárquica das Evidências para Avaliação dos Estudos (Stillwell et al., 2010). Segundo esta classificação, os níveis I e II são considerados evidências fortes, III e IV moderadas e V a VII fracas.

Salienta-se que esta revisão preservou os aspectos éticos de tal forma que todos os autores das publicações analisadas foram referenciados apropriadamente, mediante a Lei de Direitos Autorais nº 9.610 de 19 de Fevereiro de 1998 (Brasil, 1998).

\section{Resultados}

A amostra final foi composta por 07 artigos, publicados no intervalo anual entre 2011 a 2020. Em relação à abordagem das pesquisas encontradas, verifica-se que a maior parte utilizou o estudo experimental (n: 05), com nível de evidência moderado (III), seguido do ensaio clínico randomizado (n: 02), com nível de evidência forte (II).

A fim de apresentar os resultados desta revisão em um formato sinóptico, elaborou-se um quadro síntese (Quadro 1) que enfatiza informações relevantes dos estudos selecionados. É possível verificar que a Aloe vera esteve envolvida em estudos que comprovaram sua ação anti-inflamatória (redução de eritema, exsudato e dor), antimicrobiana, antioxidante, 
cicatrizante (redução do tempo para cicatrização de feridas agudas e crônicas) e hipoglicemiante (inibição de elevação da glicose pós-prandial).

Quadro 1: Síntese dos estudos avaliados quanto às principais atividades biológicas da Aloe Vera, 2022.

\begin{tabular}{|c|c|c|c|c|}
\hline $\begin{array}{l}\text { Autores } \\
\text { (ano) }\end{array}$ & Periódico & $\begin{array}{c}\text { Tipo de } \\
\text { estudo }\left(\mathrm{NE}^{*}\right)\end{array}$ & Objetivos & Principais resultados \\
\hline $\begin{array}{l}\text { Kumar et } \\
\text { al. (2011) }\end{array}$ & $\begin{array}{l}\text { Applied } \\
\text { biochemistry } \\
\text { and } \\
\text { biotechnolog } \\
\quad \mathrm{y}\end{array}$ & $\begin{array}{l}\text { Experimental } \\
\text { (III) }\end{array}$ & $\begin{array}{l}\text { Avaliar a atividade } \\
\text { hipoglicemiante do extrato } \\
\text { aquoso de Aloe vera em } \\
\text { camundongos diabéticos. }\end{array}$ & $\begin{array}{l}\text { Extrato de Aloe aquoso liofilizado }(1 \mathrm{mg} / \mathrm{ml}) \\
\text { regulou positivamente a síntese de mRNA de } \\
\text { GLUT-4 em células embrionárias de } \\
\text { camundongo NIH / 3T3. }\end{array}$ \\
\hline $\begin{array}{l}\text { Dias et al. } \\
\text { (2012) }\end{array}$ & Odontologia & $\begin{array}{l}\text { Experimental } \\
\text { (III) }\end{array}$ & $\begin{array}{l}\text { Estudar a ação do } \\
\text { fitoterápico Aloe vera na } \\
\text { cavidade anoftálmica do } \\
\text { paciente portador de prótese } \\
\text { ocular. }\end{array}$ & $\begin{array}{l}\text { Observou-se que } 93,3 \% \text { dos pacientes } \\
\text { obtiveram melhora com eliminação da } \\
\text { secreção e inflamação e destes, } 46,6 \% \\
\text { relataram melhora já na segunda semana. Foi } \\
\text { observada atividade antibiótica, analgésica e } \\
\text { anti-inflamatórias do Aloe vera. }\end{array}$ \\
\hline $\begin{array}{l}\text { Mansour } \\
\text { et al. } \\
(2014)\end{array}$ & $\begin{array}{l}\text { Journal of } \\
\text { Oral } \\
\text { Pathology \& } \\
\text { Medicine }\end{array}$ & $\begin{array}{l}\text { Ensaio clínico } \\
\text { randomizado } \\
\text { (II) }\end{array}$ & $\begin{array}{l}\text { Avaliar a eficácia clínica e a } \\
\text { segurança de géis de Aloe } \\
\text { vera. }\end{array}$ & $\begin{array}{l}\text { Foi observado efeitos cicatrizantes e anti- } \\
\text { inflamatórios, incluindo diminuição de } \\
\text { eritema, exsudação e dor. }\end{array}$ \\
\hline $\begin{array}{l}\text { Panahi et } \\
\text { al. (2015) }\end{array}$ & $\begin{array}{c}\text { Journal of } \\
\text { Wound Care }\end{array}$ & $\begin{array}{l}\text { Ensaio clínico } \\
\text { randomizado } \\
\text { (II) }\end{array}$ & $\begin{array}{l}\text { Avaliar o efeito de um } \\
\text { creme de combinação de } \\
\text { Aloe vera e azeite no } \\
\text { processo de cicatrização de } \\
\text { feridas crônicas. }\end{array}$ & $\begin{array}{l}\text { Observou-se que o creme de Aloe vera acelera } \\
\text { significativamente a cicatrização biológica de } \\
\text { feridas crônicas e ajuda a reduzir a intensidade } \\
\text { da dor. }\end{array}$ \\
\hline $\begin{array}{l}\text { Moriyam } \\
\text { a }(2016)\end{array}$ & PLoS One & $\begin{array}{l}\text { Experimental } \\
\text { (III) }\end{array}$ & $\begin{array}{l}\text { Avaliar os efeitos da Aloe } \\
\text { vera na cicatrização de } \\
\text { feridas, proliferação celular } \\
\text { e diferenciação de } \\
\text { queratinócitos epidérmicos. }\end{array}$ & $\begin{array}{l}\text { Os dados indicaram que o gel de Aloe vera } \\
\text { melhorou significativamente a cicatrização de } \\
\text { feridas em queratinócitos epidérmicos } \\
\text { primários humanos. Além disso, a análise de } \\
\text { citometria de fluxo revelou que as expressões } \\
\text { da superfície celular de } \beta 1-, \alpha 6-, \beta 4 \text {-integrina e } \\
\text { E-caderina aumentaram em queratinócitos. }\end{array}$ \\
\hline $\begin{array}{l}\text { Gorsi et } \\
\text { al. (2019) }\end{array}$ & $\begin{array}{l}\text { Pure and } \\
\text { Applied } \\
\text { Biolog }\end{array}$ & $\begin{array}{l}\text { Experimental } \\
\text { (III) }\end{array}$ & $\begin{array}{l}\text { Investigar os compostos } \\
\text { fitoquímicos presentes na } \\
\text { Aloe vera e a atividade } \\
\text { antimicrobiana } \\
\text { antioxidante do pó de gel de } \\
\text { Aloe vera com diferentes } \\
\text { solventes. }\end{array}$ & $\begin{array}{l}\text { Observou-se que o pó de gel de Aloe vera } \\
\text { pode ser usado como agente antibacteriano e } \\
\text { antioxidante na conservação de alimentos e na } \\
\text { prevenção de doenças relacionadas ao estresse } \\
\text { oxidativo. }\end{array}$ \\
\hline $\begin{array}{l}\text { Muñiz- } \\
\text { Ramirez } \\
\text { et al. } \\
\text { (2020) }\end{array}$ & $\begin{array}{l}\text { Evidence- } \\
\text { Based } \\
\text { Complement } \\
\text { ary and } \\
\text { Alternative } \\
\text { Medicine }\end{array}$ & $\begin{array}{l}\text { Experimental } \\
\text { (III) }\end{array}$ & $\begin{array}{l}\text { Avaliar os efeitos } \\
\text { antidiabéticos da }\end{array}$ & $\begin{array}{l}\text { Observou que a Aloe vera diminui a formação } \\
\text { de produtos finais de glicação avançada } \\
\text { (AGEs) e pode inibir o aumento da glicose } \\
\text { pós-prandial, sugerindo que a planta pode } \\
\text { prevenir complicações do diabetes. }\end{array}$ \\
\hline
\end{tabular}

Nota: *NE - Nível de evidência. Fonte: Autores. 


\section{Discussão}

Este estudo analisou a produção científica a respeito das principais propriedades farmacológicas da Aloe vera. Sabe-se que as plantas medicinais são bastante empregadas como terapia alternativa para tratamento de diversas patologias, devido ao seu grande potencial terapêutico. Durante muito tempo, essa prática de cuidado tradicional é utilizada e passada de geração para geração através do conhecimento empírico (Badke et al., 2016). Apesar de o uso estar relacionado ao conhecimento popular, sucessivamente elas são incluídas no conhecimento científico (Carvalho \& Conceição, 2015). Através de pesquisas, comprovaram-se as evidências de cura, fortificação do sistema imunológico e funções antineoplásica, antimicrobiana e antiinflamatória (Souza et al., 2017).

À luz dos resultados, observou-se que a Aloe vera possui excelente atividade imunomoduladora, ou seja, efeito antiinflamatório. Este efeito regula negativamente a produção de citocinas inflamatórias induzidas por lipopolissacarídeos e a expressão do inflamassoma em macrófagos humanos (Budai et al., 2013). Pesquisadores demostraram que o pré-tratamento com polissacarídeos de Aloe vera pode atenuar a lesão de isquemia cerebral e reperfusão em ratos traumático-hemorrágicos graves, através da inibição da resposta inflamatória sistêmica e da agregação leucocitária e da peroxidação lipídica no cérebro (Liu et al., 2012).

Demonstrou-se universalmente que a administração de Aloe vera resulta em aumento acentuado da atividade fagocítica e proliferativa do sistema reticuloendotelial. Ela inibe diretamente a via da ciclooxigenase e reduz a produção de prostaglandinas, que desempenham um papel importante na inflamação. Aloe vera também contém antraquinonas e cromonano, que possuem fortes efeitos anti-inflamatórios como mostrado em macrófagos murinos (Park et al., 2009). Um relatório de um estudo clínico avaliou o efeito terapêutico do gel de Aloe vera em que o gel oral a $2 \%$ é eficaz não apenas na diminuição do escore de dor e no tamanho da ferida em pacientes com estomatite aftosa recorrente, mas também na diminuição do período de cicatrização da ferida aftosa (Babaee et al., 2012).

Aloe vera também foi descrita como um agente antimicrobiano. As antraquinonas, um dos compostos ativos, agem como a tetraciclina que inibe a síntese de proteínas bacterianas bloqueando o sítio ribossômico A. Portanto, as bactérias não podem crescer no meio contendo extrato de Aloe vera. Polissacarídeos de gel de Aloe vera têm sido atribuídos a atividade bacteriana direta através da estimulação de leucócitos fagocitários para destruir bactérias. Um estudo demonstrou que o gel interno de Aloe vera expressa propriedades antibacterianas contra cepas de Helicobacter pylori suscetíveis e resistentes, propondo o gel interno de Aloe vera como um novo agente natural eficaz para combinação com antibióticos para o tratamento de infecção gástrica por H. pylori (Tan et al., 2011).

Sobre a propriedade antioxidante, a Aloe vera contém quantidades substanciais destas substâncias, incluindo $\alpha$ tocoferol (vitamina E), carotenoides, ácido ascórbico (vitamina C), flavonoides e taninos, e tem sido sugerido que a ação antioxidante pode ser uma propriedade importante de plantas medicinais usadas em tratamento de várias doenças (Kang et al., 2014). A administração de extrato etanólico de gel de Aloe vera em antioxidantes teciduais levou à redução do nível de glicose sanguínea em ratos diabéticos, o que ajuda a prevenir a formação excessiva de radicais livres por várias vias bioquímicas, além de reduzir o potencial de glicação das enzimas (Kammoun et al., 2011).

A respeito da ação cicatrizante da Aloe vera, ela afeta vários fatores que estão envolvidos no processo de cicatrização de feridas, promovendo a regeneração do tecido. Esta planta contém aminoácidos (glutamina treonina, isoleucina, valina e fenilalanina), enzimas (bradicinase, catalase, lipase, celulase, carboxipeptidase e peroxidase), polímeros (acemanana e aloverose) e constituintes vitais para a processo de cicatrização. Também possui vários eletrólitos inorgânicos, como cromo, cobre, potássio, ferro, magnésio, zinco, sódio e cálcio, que também são essenciais no processo de cicatrização de feridas (Bozzi et al., 2007). 
A Aloe vera previne a formação de cicatrizes durante a lesão da pele, estimulando a produção de células e promovendo o processo de regeneração nas camadas mais profundas da pele. Vários mecanismos de ação foram relatados para as atividades de cicatrização de feridas por meio de géis com substrato de Aloe vera, como aumento da migração de células epiteliais, manutenção da ferida úmida, redução da inflamação e rápida maturação do colágeno (Moriyama et al., 2016).

Acemanano, um dos principais constituintes ativos do gel de Aloe vera, acelera a cicatrização de feridas e ativa os macrófagos para estimular a produção de citocinas fibróticas. Outro composto ativo, chamado manose-6-fosfato, desempenha um papel significativo no tratamento de queimaduras de $1^{\circ}$ e $2^{\circ}$ graus (Liu et al., 2010). Foi demonstrado que a Aloe vera impede o tromboxano, que atua como um inibidor de cicatrização de feridas e resulta em melhores mecanismos de cicatrização de feridas (Hekmatpou et al., 2019).

Nesta perspectiva, pesquisadores analisaram que a Aloe vera é eficaz na cicatrização da lesão cirúrgica e no alívio da dor, uma vez que ela aumenta a síntese de colágeno no tecido de granulação, assim como aumenta a proliferação de fibroblastos, proporcionando resistência e integridade para a derme e outros tecidos. Além disso, a planta tem efeito antimicrobiano, o qual está relacionado com os seus constituintes, entre eles as antraquinonas e aloe-emodina, que podem contribuir para a redução da dor e promoção da cicatrização de feridas (Chine et al., 2017).

No que tange ao uso popular de géis de Aloe vera no tratamento de queimaduras, as evidências corroboram para a segurança do uso tópico, bem como salientam atividade bacteriostática contra os principais microrganismos responsáveis por infecção em pacientes queimados. Enfatiza-se ainda, que outras propriedades da planta podem ser responsáveis por acelerarem a cicatrização, quando comparada aos métodos convencionais de tratamento (Dias, 2016).

Ainda à luz dos resultados, verificou-se que a Aloe vera também possui propriedades hipoglicemiantes. Estudos in vivo e in vitro demonstram fortemente que a fração solúvel em água de Aloe vera possui atividades redutoras de glicose e alguns de seus componentes modulam a expressão do mRNA do transportador de glicose-4 (Alinejad-Mofrad et al., 2015). De acordo com o ensaio clínico de Kumar et al (2011), o efeito do extrato de Aloe vera foi comparado ao efeito da Metformina, um medicamento utilizado no tratamento do diabetes mellitus. O estudo permitiu concluir que a administração do gel de Aloe vera provocou o aumento da transcrição do GLUT-4, uma vez que os efeitos estimulantes do gel em proteínas do citoesqueleto permitiram um melhor tráfego no transporte das proteínas GLUT-4 do citoplasma para a membrana plasmática, favorecendo uma melhor e maior absorção da glicose pelos tecidos do organismo tratado.

\section{Conclusão}

Numerosas atividades biológicas foram atribuídas a Aloe vera ao longo dos anos, especialmente por causa da combinação dos diversos compostos ativos existentes em sua composição. Verificou-se que a Aloe vera possui diversas propriedades farmacológicas, como ação anti-inflamatória, antimicrobiana, antioxidante, cicatrizante e hipoglicemiante. Muitos usos tradicionais também são relatados, como queimaduras, eczema, cosméticos, inflamação e febre, que continuam a ser estudados, e mais pesquisas ainda precisam ser feitas. No futuro, estudos controlados com maiores números de participantes são necessários para comprovar a eficácia da Aloe vera sob várias condições e para que seja definida dose e forma segura para o seu uso.

\section{Referências}

Alinejad-Mofrad, S., Foadoddini, M., Saadatjoo, S.A. \& Shayesteh, M. (2015). Improvement of glucose and lipid profile status with Aloe vera in pre-diabetic subjects: a randomized controlled-trial. J Diabetes Metab Disord. 14, 22.

Babaee, N., Zabihi, E., Mohseni, S. \& Moghadamnia, A.A. (2012). Evaluation of the therapeutic effects of Aloe vera gel on minor recurrent aphthous stomatitis. Dent Res J (Isfahan). 9, 381-5. 
Badke, M.R., Somavilla, C.A., Heisler, E.V., Andrade, A., Budó, M.L.D. \& Garlet, T.M.B. (2016). Saber popular: uso de plantas medicinais como forma terapêutica no cuidado à saúde. Revista de Enfermagem da UFSM. 6(2), 225-34.

Balbinot, S., Velasquez, P.G. \& Düsman, E. (2013). Reconhecimento e uso de plantas medicinais pelos idosos do Município de Marmeleiro - Paraná. Rev. bras. plantas med. 15(4), 632-8.

Bontempo, M. (2012). O livro definitivo da Aloe vera, a planta milenar da saúde. Brasília: Ed: Thesaurus.

Bozzi, A., Perrin, C., Austin, S. \& Vera, F.A. (2007). Quality and authenticity of commercial Aloe vera gel powders. Food Chem. 103, 22-30.

Brasil. Ministério da Saúde (MS). (1998). Lei no 9.610, de 19 de fevereiro de 1998, que altera, atualiza e consolida a legislação sobre direitos autorais e dá outras providências. Diário Oficial da União. Brasília: Ministério da Saúde. http://www.planalto.gov.br/ccivil_03/leis/19610.htm

Budai, M.M., Varga, A., Milesz, S., Tőzsér, T. \& Benko, S. (2013). Aloe vera downregulates LPS-induced inflammatory cytokine production and expression of NLRP3 inflammasome in human macrophages. Mol Immunol. 56, 471-9.

Carvalho, A.P.S. \& Conceição, G.M. (2015). Utilização de plantas medicinais em uma área da estratégia de saúde da família, Caxias, Maranhão. Enciclopédia biosfera, Centro Científico Conhecer - Goiânia, 11(21), 3477-88.

Carvalho, R.A., Lima, A.M.C., Pereira, A.I.S., Sobrinho, O.P.L., Ribeiro, F.A.A., Costa, S.T.S., et al. (2020). Potencialidades Farmacológicas da Babosa: um estudo realizado por meio das técnicas de prospecção científica e tecnológica. Cadernos de Prospecção. 13(1), 184-96.

Chini, L.R., Mendes, R.A., Siqueira, L.R., Silva, S.P., Silva, P.C.S., Dázio, E.M.R., et. al. (2017). O uso do Aloe sp (babosa) em feridas agudas e crônicas: revisão integrativa. Aquichan. 17(1), 7-17.

Dias, J. L. (2016). Avaliação in vitro da atividade antimicrobiana e do potencial citotóxico do gel de Aloe Vera: uma discussão sobre o uso em queimaduras. Dissertação (Mestrado em Ciências da Saúde) - Universidade Federal do Tocantins, Programa de Pós-Graduação em Ciências da Saúde, Palmas.

Dias, R.B.E., Mello, D.N.P., Nigro, R.C. \& Coto, N.P. (2012). Estudo prospectivo da utilização do Aloe vera nas afecções da cavidade anoftálmica em portadores de prótese ocular. Odontologia. 20(39), 141-3.

Farias, C.F.A. (2020). Estudo da eficácia da Aloe vera como crioprotetor vegetal na criopreservação de espermatozoide caprino. Dissertação (Mestrado) UFPB/CCA. João Pessoa.

Freitas, V.S., Rodrigues, R.A.F. \& Gaspi, F.O.G. (2014). Propriedades farmacológicas da Aloe vera (L.) Burm. f. Rev. bras. plantas med. 16(2), $299-307$.

Gorsi, F.I., Kausar, T. \& Murtaza, M.A. (2019). Evaluation of antibacterial and antioxidant activity of Aloe vera (Aloe barbadensis Miller) gel powder using different solvents. Pure and Applied Biology. 8(2), 1265-70.

Hekmatpou, D., Mehrabi, F., Rahzani, K. \&Aminiyan, A. (2019). The Effect of Aloe Vera Clinical Trials on Prevention and Healing of Skin Wound: A Systematic Review. Iran J Med Sci. 44(1), 1-9.

Kammoun, M., Miladi, S., Ben Ali, Y., Damak, M., Gargouri, Y. \& Bezzine, S. (2011) In vitro study of the PLA2 inhibition and antioxidants activities of Aloe vera leaf skin extracts. Lipids Health Dis. 10(30).

Kang, M.C., Kim, S.Y., Kim, Y.T., Kim, E.A., Lee, S.H., Ko, S.C., et al. (2014). In vitro and in vivo antioxidant activities of polysaccharide purified from Aloe vera (Aloe barbadensis) gel. Carbohydr Polym. 99, 365-71.

Kumar, R., Sharma, B., Tomar, N.R., Roy, P., Gupta, A.K. \& Kumar, A. 2011. In vivo evalution of hypoglycemic activity of Aloe spp. and identification of its mode of action on GLUT-4 gene expression in vitro. Appl Biochem Biotechnol. 164(8), 1246-56.

Lima, R.M.F., Santos, D.B., Marcílio, T.V., Lima, C.A.S. \& Souza, V.V. (2012). Desenvolvimento de sabonete líquido de Aloe vera: extração, purificação do extrato ativo e manipulação da forma farmacêutica. Revista da Universidade Vale do Rio Verde. 10(2), 251-9.

Liu, L.Y., Chen, X.D., Wu, B.Y \& Jiang, Q. (2010). Influence of Aloe polysaccharide on proliferation and hyaluronic acid and hydroxyproline secretion of human fibroblasts in vitro. Journal of Chinese Integrative Medicine. 8(3), 256-62.

Liu, Z., Ge, X., Lu, Y., Dong, S., Zhao, Y. \& Zeng, M. (2012). Effects of chitosan molecular weight and degree of deacetylation on the properties of gelatinebased films. Food Hydrocolloids. 26, 311-7.

Maenthaisong, R., Chaiyakunapruk, N., Niruntraporn, S. \& Kongkaew, C. (2007). The efficacy of aloe vera used for burn wound healing: A systematic review. Burns. 33(6), 713-8.

Mansour, G., Ouda, S., Shaker, A. \& Abdallah, H.M. (2014). Clinical efficacy of new aloe vera- and myrrh-based oral mucoadhesive gels in the management of minor recurrent aphthous stomatitis: a randomized, double-blind, vehicle-controlled study. J Oral Pathol Med. 43(6), 405-9.

Moriyama, M. (2016). Beneficial Effects of the Genus Aloe on Wound Healing, Cell Proliferation, and Differentiation of Epidermal Keratinocytes. PLoS One. 11(10), e0164799.

Muñiz-Ramirez, A., Perez, R.M., Garcia, E. \& Garcia, F.E. (2020). Antidiabetic Activity of Aloe vera Leaves. Evid Based Complement Alternat Med. 6371201.

Nascimento, J.W.A., Santos, R.S., Santos, T.M.R., Silva, A.L.B., Rodrigues, L.D.C., Silva, V.W., et al. (2021) Complications associated with intimate partner violence in pregnant women: a systematic review. Int. J. Dev. Res. 11(7), 48924-8. 
Research, Society and Development, v. 11, n. 3, e6311326062, 2022

(CC BY 4.0) | ISSN 2525-3409 | DOI: http://dx.doi.org/10.33448/rsd-v11i3.26062

Panahi, Y., Izadi, M., Sayyadi, N., Rezaee, R., Jonadi-Jafari, N., Beiraghdar, F., et al. (2015). Comparative trial of Aloe vera/olive oil combination cream versus phenytoin cream in the treatment of chronic wounds. J Wound Care. 24(10), 459-60.

Park, M.Y., Kwon, H.J. \& Sung, M.K. (2009). Evaluation of aloin and aloe-emodin as anti-inflammatory agents in aloe by using murine macrophages. Biosci Biotechnol Biochem. 73, 828-32.

Souza, J.R.S., Silva, R.H. \& Zanachi, J.A. (2017). Características fitoterapêuticas da Aloe vera. Revista Funec Científica - Multidisciplinar. 6(8), 23-9.

Souza, C.A.O., Júnior, D.L.S., Monteiro, M.F.G., Aquino, P.E.A., Saraiva, C.R.N., et al. (2020). Atividade antibacteriana direta e combinada do extrato etanólico de Aloe vera (babosa). Revista UNILUS Ensino e Pesquisa. 17(48), 171-85.

Stillwell, S., Melnyk, B.M., Fineout-Overholt, E. \& Williamson, K. (2010). Evidence- based practice: step by step. Am J Nurs. 110(5), 41-7.

Tan, Z., Li, F. \& Xing, J. (2011). Separation and purification of Aloe anthraquinones using PEG/salt aqueous two-phase system. Sep Sci Technol. 46, 1503-10.

Vignini, S. (2011). A inteligência biológica numa visão quântica e sistêmica: apresentação de uma proposta terapêutica. São Paulo. Ed: Scortecci. 